\title{
Malignant Lymphomas of Waldeyer's Ring : Natural History and Survival after Radiotherapy
}

\author{
ALBERTO BANFI, GIANNI BONADONNA, SANTE BASSO RICCI, FRANCO MILANI, \\ ROBERTO MOLINARI, SILVIO MONFARDINI, ROBERTO ZUCALI
}

British Medical fournal, 1972, 3, 140-143

\section{Summary}

The natural history of 292 consecutive cases of reticulum cell sarcoma and lymphosarcoma of Waldeyer's ring and the survival rate after radiotherapy are reported. In our institute since 1928 from 30 to $35 \%$ of pharyngeal neoplasms have been lymphomas, and of these $55 \%$ have been reticulum cell sarcomas, $21 \%$ lymphosarcomas, and $1 \%$ Hodgkin's disease. This high incidence may probably be ascribed to the fact that in all malignant lymphomas, irrespective of the clinical presentation, a systematic biopsy of the whole Waldeyer's ring was carried out. Pharyngeal lymphomas were confined to Waldeyer's ring in $19 \cdot 6 \%$ of cases, with initial spread to contiguous cervical nodes in $43.8 \%$, to distant nodes in $24.2 \%$, and to extranodal tissues in $12.4 \%$. Lymphography showed abnormal retroperitoneal lymph nodes in $38.3 \%$ of cases. There was gastrointestinal involvement either initially or later in $17.6 \%$ of cases. High-energy radiation therapy to both sides of the neck was the treatment of choice for local and regional disease. It achieved a five-year survival rate of $41.9 \%$ in the group of 97 patients treated during the past decade. The incidence of relapse (recurrence and new manifestations) was highest in the first year after treatment.

\section{Introduction}

Malignant lymphomas are found more commonly than other forms of pharyngeal neoplasms in western countries (Banfi et al., 1970). With few exceptions (Musshoff et al., 1971) the lymphoid tissue in Waldeyer's ring (the nasopharynx, tonsils, oropharynx, and soft palate) is involved in not more than $10-15 \%$ of all cases of malignant lymphoma (Rosenberg et al., 1961; Fuller, 1967). Moreover, the lymphoma seems to arise from the tonsil more often than from the nasopharyngeal space (Catlin, 1966; McNelis and Pai, 1969; Terz and Farr, 1969; Tikka and Malmio, 1969; Prosnitz et al., 1969; Wang, 1969; Al-Saleem et al., 1970; Robinson et al., 1971). At the National Cancer Institute of Milan the incidence of pharyngeal lymphomas since 1928 has ranged from 30 to $35 \%$ of all pharyngeal neoplasms, and of the lymphomas $55 \%$ have been cases of reticulum cell sarcoma, $21 \%$ cases of lymphosarcoma, and $1 \%$ cases of Hodgkin's disease.

There are very few reports dealing specifically with the natural history and treatment of malignant lymphomas of Waldeyer's ring. This paper records our experience in a large

Naitonal Cancer Institute, Milan, Italy

ALBERTO BANFI, M.D., Director, Division of Radiology; Associate Professor of Radiology, Úniversity of Milan

GIANNI BONADONNA, M.D., Associate Director, Division of Clinical Oncology $\mathrm{F}$

ROBERTO MOLINARI, M.D., Associate Director, Division of Clinical Oncology E SILVIO MONFARDINI, M.D., Clinical Assistant, Division of Clinical

SANTE BASSO RICCI, M.D., Clinical Assistant, Division of Radiology; Assistant Professor of Radiology, University of Milan

FRANCO MILANI, M.D., Clinical Assistant, Division of Radiology; Assistant Professor of Radiology, University of Milan

ROBERTO ZUCALI, M.D., Clinical Assistant, Division of Radiology; Assistant Professor of Radiology, University of Milan number of cases, and also compares the survival rate in patients who were investigated by lymphography before treatment with that in patients who were not investigated by lymphography.

\section{Patients and Methods}

Altogether 292 consecutive patients suffering from lymphoma of Waldeyer's ring who attended our institute from January 1950 to June 1971 were studied. A preliminary evaluation of the first 144 patients in this group was carried out by Carnevali and Salvini (1968). The results in patients treated from 1928 to 1949 have been published elsewhere (Luzzatti, 1960).

\section{INVESTIGATIONS}

Most of the patients were investigated as inpatients. In all cases tissue for biopsy was taken from the primary tumour in Waldeyer's ring and in about one-fifth of the cases from the superficial enlarged lymph nodes. Radiological examination included lateral films and tomography of the pharynx, examination of the base of the skull and of the chest, and a skeletal survey. Lowerlimb lymphography, accompanied in most cases by $x$-ray examination of the gastrointestinal tract, was carried out in 107 of the 153 patients investigated after January 1962. In the remaining 46 patients the retroperitoneal space was explored by combining intravenous urography and pneumoretroperitoneum with tomography when abdominal symptoms and signs were present or suspected. Gastroscopy with biopsy was performed in 37 cases, and diagnostic laparotomy with splenectomy in three cases. In patients with suspicious or evident hepatomegaly a liver scan was performed with ${ }^{108} \mathrm{Au}$, and liver biopsy was carried out either through peritoneoscopy or through a Menghini needle.

Laboratory investigations were carried out routinely or as indicated by circumstances, and data were systematically recorded in patients seen after 1962 .

\section{STAGE CLASSIFICATION}

We classified the stages of the disease as follows:

Local Stage.-Tumour localized to the pharynx. Cases with extension to contiguous tissues (base of skull, nasal and paranasal cavities) were also included.

Regional Stage.-Tumour involving the pharynx and the lymph nodes of either the neck or the supraclavicular fossa or both.
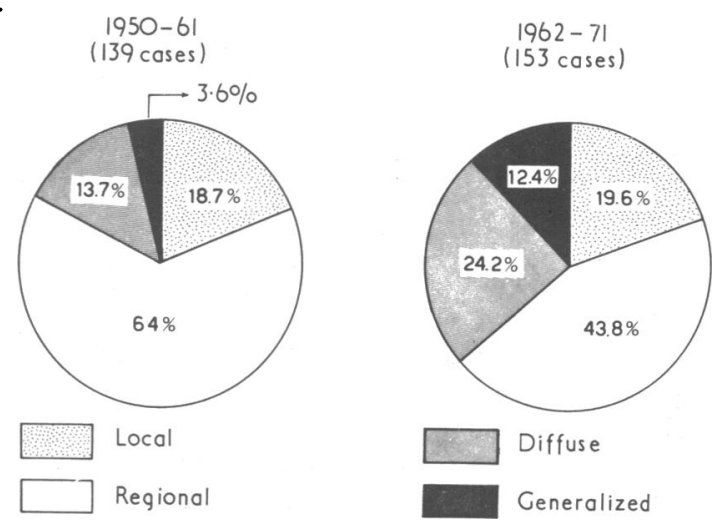

FIG. 1-Percentages of patients in the various stages of the disease before treatment seen during the periods $1950-61$ and 1962-71. 
Diffuse Stage.-Tumour involving the pharynx (with or without node involvement) and distant lymphoid regions, including the spleen.

Generalized Stage.-Tumour involving the pharynx (with or without regional and distant node involvement) and viscera or other tissues (gastrointestinal tract, bones, liver, skin, etc.).

The percentage of cases in each stage is shown in Fig. 1.

\section{HISTOLOGICAL CLASSIFICATION}

Though a nodular and a diffuse pattern as well as different cytological types (well differentiated, poorly differentiated, stem cell, histiocytic) of malignant lymphoma can be recognized, we still used the terms lymphosarcoma and reticulum cell sarcoma. For simplicity the six cases with mixed forms (lymphoreticulum cell sarcoma) were included in the reticulum cell sarcoma group. Therefore 248 cases were classified as reticulum cell sarcoma and 44 as lymphosarcoma, a ratio of about five to one.

\section{TREATMENT}

Obviously there were changes in therapy during the 21 years covered by our study. From 1950 until the end of 1961 patients were irradiated with $250 \mathrm{kV}$ and given alkylating agents. In the local and regional stages of the disease the tumour dose was $3,000-4,000$ rads over four to five weeks, while in the other two stages the dose varied according to the case. Prophylactic irradiation of the cervical area was not carried out in cases in the local stage, and chemotherapy was usually given only to patients resistant to radiotherapy or to those with visceral involvement.

From 1962 to 1971 patients were treated with cobalt therapy and with various drugs as they became available. In the local and regional stages of the disease the tumour dose was 4,5005,000 rads over four to five weeks, while in the diffuse stage a dose usually not exceeding 3,500-4,000 rads was given to areas of distant node involvement. Prophylactic irradiation of both sides of the neck was given to all patients in the local stage, and in cases of unilateral cervical lymph node involvement both sides of the neck were always irradiated. From 1970 an intensive five-drug regimen was also adopted for cases of lymphoreticular sarcoma in the diffuse and generalized stages.

\section{FOLLOW-UP}

After treatment was completed the patients were followed up at intervals of one to three months. In patients with local, regional, and diffuse disease a complete blood count and a chest $x$-ray examination were performed about three times a year. A radiographic check was made on the retroperitoneal nodes in all patients who had been investigated by lymphography so long as contrast material was present. When recurrence was suspected both intravenous urography and $x$-ray examination of the gastrointestinal tract were carried out, and in a few cases a second lymphogram was taken. $X$-ray examination of the gastrointestinal tract in asymptomatic patients was done twice a year for the first three years. Skeletal survey was repeated only when the patient complained of bone pain.

\section{Results}

Analysis of the sex distribution in the 292 cases gave a sex ratio of 1.8 to 1 in favour of males. The peak of incidence was during the fifth, sixth, and seventh decades; however, 37 patients were aged under 30 . This shows in comparison with carcinomas that lymphoreticular sarcomas of the pharynx occur in younger patients.

In about half of the cases $(44 \cdot 2 \%)$ the first sign of disease was involvement of cervical nodes, while local symptoms (nasal obstruction, earache, deafness, lump in the throat, etc.) were the first sign in $52.4 \%$ of the cases. In only $2.7 \%$ of the cases was distant nodal involvement the first sign, and involvement of extranodal tissues was the first sign in $0.7 \%$.

The distribution of cases according to the site of the primary tumour within Waldeyer's ring is shown in Table I. The naso-

TABLE I-Site of Primary Lesion within Waldeyer's Ring in 292 Cases

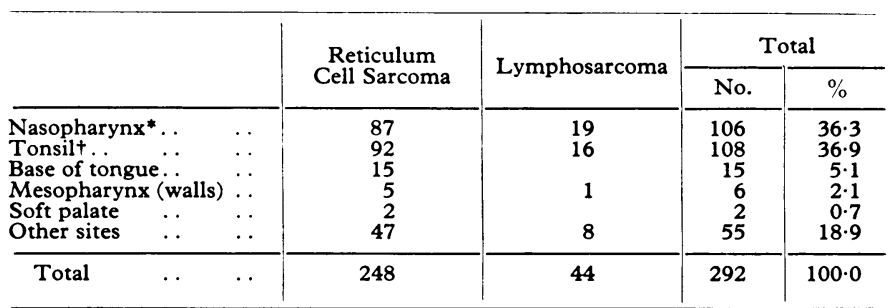

* Seven patients had clinical and radiological signs of invasion of the base of the skull while in five cases there was invasion of the nasal and paranasal cavities. tIn 15 cases the involvement of tonsil was bilateral.

pharynx and tonsil were the primary site in almost equal numbers of cases. Pharyngeal lymphomas typically affect sites within Waldeyer's ring (especially nasopharynx and tonsil as well as both tonsils) more often than do pharyngeal carcinomas, and our results illustrate this. In only 12 of the 292 cases, however, was the tumour invading contiguous tissues.

The value of lymphography in establishing the clinical stage of the disease is shown in Fig. 2. Abnormal retroperitoneal

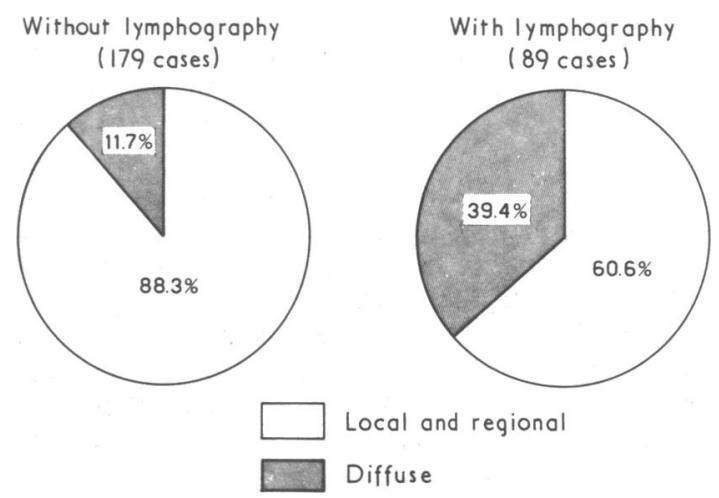

FIG. 2-Stage of disease before treatment in patients investigated by lymphography and in those not so investigated (patients in the generalized stage excluded).

nodes were found in $41(38.3 \%)$ of the 107 patients examined by lymphography. It is notable that in $48 \%$ of those with a positive lymphogram the inguinal nodes were not palpable, and that in four the lymphoma was apparently confined to Waldeyer's ring. Thus in these cases lymphography played an essential part in discovering occult disease.

The overall incidence of axillary, mediastinal, and splenic involvement before treatment was $10.9 \%, 5.1 \%$, and $1 \%$ respectively, but in patients with diffuse and generalized disease the corresponding figures were $41.2 \%, 18.5 \%$, and $3.7 \%$. In all but one of the patients with mediastinal lymph node involvement the cervical nodes were affected, but splenic involvement was associated with retroperitoneal involvement in only $5 \%$ of the cases.

The pattern of visceral involvement in cases in the generalized (extranodal) stage of the disease is shown in Table II. The

TABLE II-Incidence of Extranodal Involvement before and after Therapy (all Cases)

\begin{tabular}{c|c|c|c|c|c|c}
$\begin{array}{c}\text { Time } \\
\text { of } \\
\text { Diagnosis }\end{array}$ & $\begin{array}{c}\text { Gastro- } \\
\text { intestinal } \\
\text { Tract }\end{array}$ & Liver & Skin & Lung & $\begin{array}{c}\text { Bone } \\
\text { Marrow }\end{array}$ & Bone \\
\hline $\begin{array}{c}\text { Before therapy } \\
\text { After therapy }\end{array}$ & $\begin{array}{c}11 \\
21\end{array}$ & $\begin{array}{c}10 \\
13\end{array}$ & $\begin{aligned} 1 \\
14\end{aligned}$ & $\begin{array}{c}1 \\
5\end{array}$ & $\begin{array}{c}5 \\
3\end{array}$ & 7 \\
\hline Total & 32 & 23 & 15 & 13 & 8 & 7 \\
\hline
\end{tabular}


gastrointestinal tract and the liver predominate, while skin, lung, and bone were more often involved later in the course of the disease. Extrinsic cells in the bone marrow were detected in fewer than 3\% of the cases, and in these the terminal course of the disease was similar to that of an acute leukaemia. Extranodal involvement was the first and only sign of recurrence in 16 out of 68 patients who relapsed after radiotherapy in the local or regional stage of the disease.

The overall incidence of gastrointestinal involvement of $10.9 \%$ (Table III) represents an incidence of $3.6 \%$ in patients

TABLE III-Number of Patients with Gastrointestinal Involvement before and after Treatment

\begin{tabular}{|c|c|c|c|c|}
\hline $\begin{array}{c}\text { Time } \\
\text { of } \\
\text { Diagnosis }\end{array}$ & Stomach & $\begin{array}{c}\text { Large } \\
\text { Intestine }\end{array}$ & $\begin{array}{c}\text { Stomach and } \\
\text { Large } \\
\text { Intestine }\end{array}$ & Total \\
\hline $\begin{array}{l}\text { Initial evaluation. } \\
0-5 \text { Months } \\
\text { 6-11 Months } \\
12-23 \text { Months } \\
\text { After } 2 \text { years }\end{array}$ & $\begin{array}{l}9 \\
4 \\
6 \\
7 \\
2\end{array}$ & 1 & $\begin{array}{l}1 \\
1\end{array}$ & $\begin{array}{r}11 \\
6 \\
6 \\
7 \\
2\end{array}$ \\
\hline Total $\ldots$ & 28 & 2 & 2 & $32(10.9 \%)$ \\
\hline
\end{tabular}

seen from 1950 to 1961 and of $17.6 \%$ in those seen from 1962 to 1971. This emphasizes the diagnostic importance of the systematic radiological examination of the gastrointestinal tract carried out in most patients in the later group. Gastrointestinal lymphoma was found in 30 of the 32 cases, and in 28 of them only the stomach was involved. In about one-third of the cases the gastric involvement was detected when the patient was first seen, while in most of the others it was discovered within two years. Of the 21 patients in whom the gastrointestinal involvement was discovered during follow-up the disease was initially staged as local in 3, regional in 14, and generalized in 4 . In 13 cases the gastric involvement was the first and only sign of a relapse.

The highest incidence of recurrence in cases initially in the local and regional stages occurred within a year after therapy (Table IV). In 51 cases $(46 \%)$ the recurrence was in the form of new manifestations of the disease in lymphoid tissue, mainly above the diaphragm (Table V), where the principal sites were the neck $(23.6 \%)$ when prophylactic irradiation had not been carried out and the axillae $(20 \cdot 8 \%)$.

The 10-year survival in all cases treated with radiotherapy is shown in Fig. 3. The highest mortality in both types of tumour is in the first two years. The tendency of the curves to level out

TABLE IV-Site of Recurrence after Radiation Therapy in Patients in the Local or Regional Stage

\begin{tabular}{|c|c|c|c|c|}
\hline \multirow{2}{*}{\multicolumn{2}{|c|}{$\begin{array}{l}\text { Interval from } \\
\text { Radiotherapy }\end{array}$}} & \multirow{2}{*}{$\begin{array}{c}\text { Local } \\
\text { Recurrence }\end{array}$} & \multicolumn{2}{|c|}{ New Manifestations } \\
\hline & & & $\begin{array}{l}\text { Lymph Node } \\
\text { and/or Spleen }\end{array}$ & Extranodal \\
\hline $\begin{array}{l}0-11 \text { Months } \\
1-2 \text { Years } \\
2-3 \text { Years } \\
\text { After } 3 \text { years }\end{array}$ & $\begin{array}{l}\cdots \\
\cdots \\
\cdots\end{array}$ & $\begin{array}{r}24 \\
6 \\
5\end{array}$ & $\begin{array}{r}40 \\
7 \\
1 \\
3\end{array}$ & $\begin{array}{r}17 \\
5 \\
2 \\
1\end{array}$ \\
\hline Total. . & . & $35(31.5 \%)$ & $51(46 \%)$ & $25(22.5 \%)$ \\
\hline
\end{tabular}

TABLE v-Site of New Lymphoid Manifestations in 51 Patients in the Local or Regional Stage when First Seen

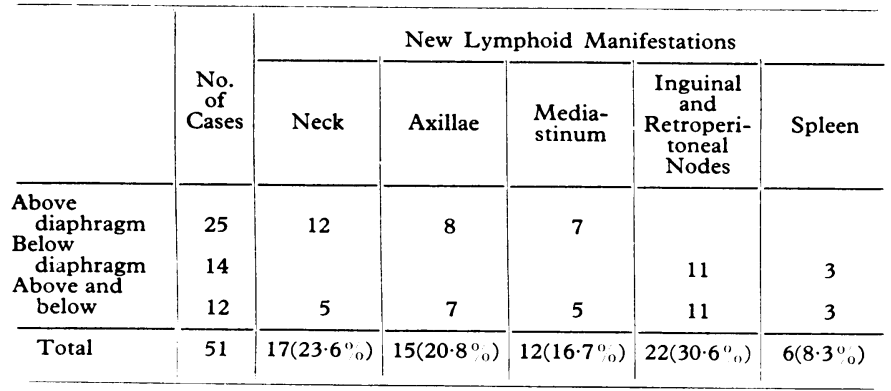

from the fifth year can be ascribed to natural mortality. The difference in the slope of the curves and in the median survival rates is not meaningful since the number of cases of reticulum cell sarcoma was about six times more than those of lymphosarcoma. We were unable, therefore, to show any difference in prognosis in the two types. The five-year and 10-year survival rates are, in fact, about the same. On the other hand, the stage of the disease before treatment seems significantly to affect survival (Fig. 4).

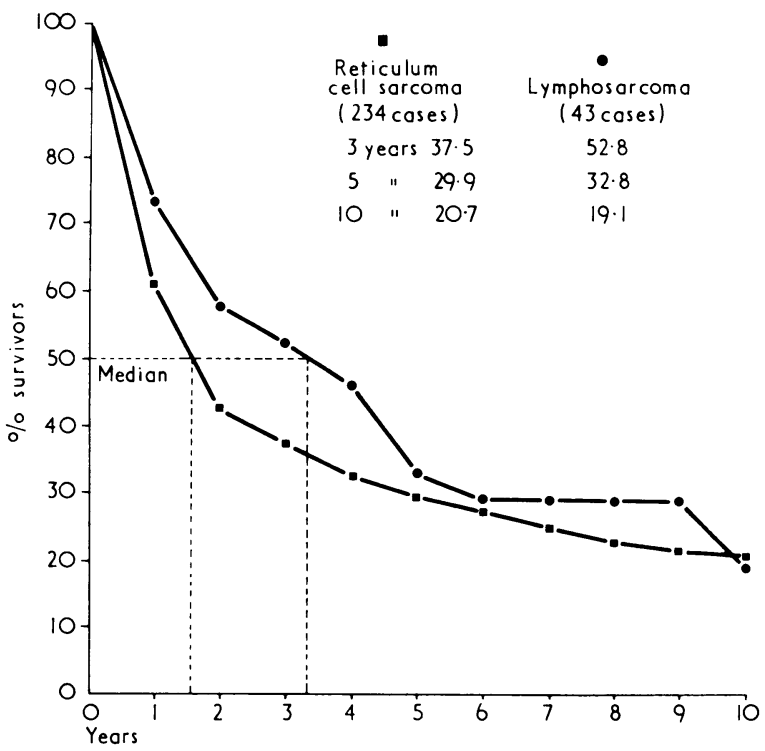

FIG. 3-Survival rates in patients with reticulum cell sarcoma and patients with lymphosarcoma (local and regional stages of the disease).

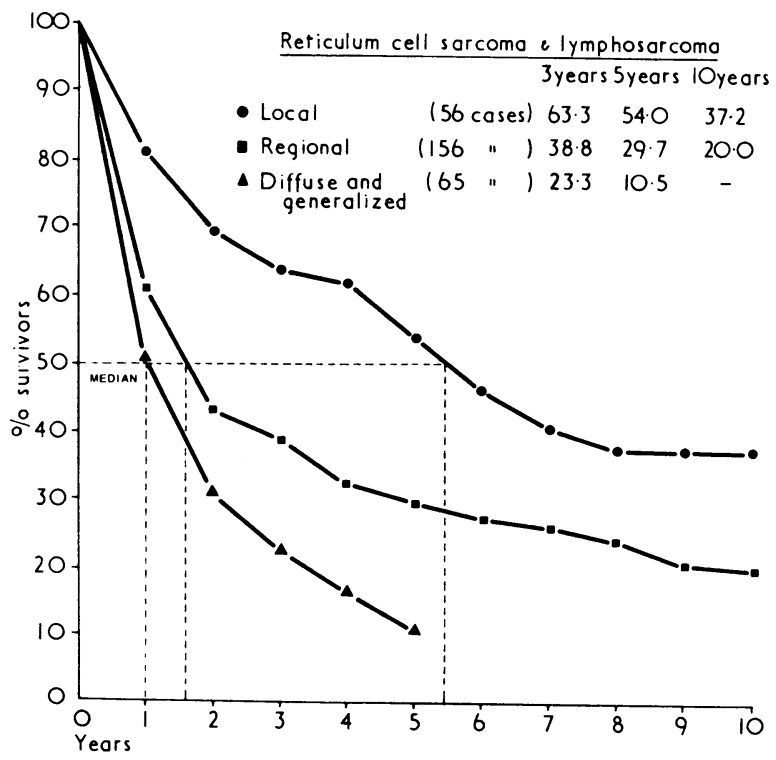

FIG. 4-Survival rates after radiotherapy in patients in different stages of the disease. The 10-year survival for diffuse and generalized disease has not been calculated because of too few cases.

No significant difference in survival was found in relation to age, sex, or site of the primary lymphoma within Waldeyer's ring. The survival rates in groups of patients with local and regional disease treated in different periods are given in Table VI. The similarity of the rates in patients treated in the first period (1928-49) and in patients treated in the second period (1950-61) may be attributed to a similarity of diagnostic and radiotherapeutic (low tissue dose, no prophylactic irradiation of the neck) techniques used in the two periods. A better survival rate, however, is evident among the patients in the third period 
TABLE VI-Survival Rate of Patients in the Local or Regional Stage of Disease Treated in Different Periods

\begin{tabular}{|c|c|c|c|c|}
\hline \multirow{2}{*}{$\begin{array}{l}\text { Periods of } \\
\text { Treatment }\end{array}$} & \multirow{2}{*}{ No. of Cases } & \multicolumn{3}{|c|}{ Survival Rate* } \\
\hline & & 3-year & 5-year & 10-year \\
\hline $\begin{array}{l}1928-49 \\
1950-61 \\
1962-71\end{array}$ & $\begin{array}{r}123 \\
115 \\
97\end{array}$ & $\begin{array}{l}33 \cdot 3 \% \\
36.5 \% \\
57.5 \%\end{array}$ & $\begin{array}{l}26.4 \% \\
30.4 \% \\
41.9 \%\end{array}$ & $\begin{array}{l}16.8 \% \\
19.6 \%\end{array}$ \\
\hline
\end{tabular}

Calculated by actuarial analysis.

(1962-71). So far there is a significant difference between patients in the 1950-61 group and those in the 1962-71 group only in the three-year survival rate $\left(\chi^{2}=9.46 ; P<0.01\right)$. There is no such difference in the five-year rate $\left(\chi^{2}=2.71 ; P>0.05\right)$, and comparison of the 10-year survival rates is not yet possible. The improvement in the three-year survival rate can be attributed to more accurate assessment of the stage of the disease by means of lymphography and skeletal and gastrointestinal radiography, and to more aggressive radiotherapy (cobalt therapy with prophylactic irradiation in patients with local and regional lymphoma).

\section{Discussion}

It seems appropriate for both diagnostic and therapeutic reasons to distinguish pharyngeal sarcomas as a separate clinical entity within the group of malignant lymphomas.

The following facts emerge from an analysis of our series of cases. (1) The evidence of pharyngeal involvement at the time of diagnosis was high in all cases of lymphoreticular sarcoma, particularly in cases of reticulum cell sarcoma. The opposite occurs for Hodgkin's disease. (2) In about two-thirds of the cases the disease was limited to the primary pharyngeal tumour or to the cervical lymph nodes (local or regional stage). (3) Some cases in the local stage can be cured with only local treatment (radiotherapy or surgery). (4) Involvement of Waldeyer's ring by malignant lymphomas originating in lymphoid tissue other than in the neck is extremely rare. (5) Pharyngeal lymphomas tend to involve more than one site in Waldeyer's ring, both initially and subsequently. (6) In contrast to the mode of spread of nodal lymphoreticular sarcomas (Banfi et al., 1968), pharyngeal lymphomas, like pharyngeal carcinomas, spread initially to the cervical nodes. Local aggressive forms spread to surrounding tissues (base of skull, nasal cavities, paranasal sinuses, etc.) in the same way.

The presence of gastrointestinal involvement in some of our patients might seem to challenge the generally accepted belief that malignant lymphomas originate in one focus. In about $6 \%$ of our patients in the group seen from 1962 to 1971 a gastric lymphoma was present when the patient was first investigated. Furthermore, in $9 \%$ of patients gastric involvement was found during the first two years of follow-up as an apparently new manifestation of the disease. These findings suggest that in some cases a lymphoma may arise simultaneously in Waldeyer's ring and in the gastrointestinal tract-especially the stomach. This would explain those cases apparently in the local or regional stage affecting the head and neck where lymphography shows involvement of retroperitoneal lymph nodes. We think it is possible that in some cases a primary gastric focus exists which does not show on conventional radiography and only the resultant retroperitoneal node involvement can be detected by lymphography. An alternative hypothesis might be that neoplastic cells from the primary lesion in the pharynx are swallowed and implanted in the gastric mucosa. We think this improbable because this does not occur in pharyngeal carcinomas.

Study of the natural history of pharyngeal lymphomas emphasizes that their incidence is higher than has been thought
(Rosenberg et al., 1961; Fuller, 1967). Preselection by referrals from other hospitals only partly explains the high incidence in our series. We believe it was because we systematically examined Waldeyer's ring by biopsy in every case irrespective of the clinical presentation. In fact, in almost half of the present cases the first clinical sign of disease was a cervical adenopathy. A lymphoreticular sarcoma tends to spread first to regional lymph nodes-to cervical nodes from a primary growth in Waldeyer's ring and retroperitoneal nodes from a lesion in the gastrointestinal tract.

High-energy irradiation extending from the base of the skull to both supraclavicular fossae is the treatment of choice in patients with local or regional disease. The three-year and five-year survival rates in our third group of patients with local and regional disease are similar to those reported by others in fewer patients (Fuller, 1967; Prosnitz et al., 1969; Terz and Farr, 1969; Wang, 1969; Al-Saleem et al., 1970; Robinson et al., 1971). Although, however, the survival rate was not significantly different in the two types of disease in our series, Fuller (1967) and Al-Saleem et al. (1970) found survival rates of 57\% and $58 \%$ respectively in lymphosarcoma and $19 \%$ and $38 \%$ in reticulum cell sarcoma. Al-Saleem et al. also showed that the prognosis in undifferentiated lymphoma is extremely poor. Terz and Farr (1969) noted that the five-year survival rate sharply decreased in proportion to the extent of regional lymph node involvement (from $50 \%$ when only the submental nodes were involved to nil when the disease extended to the supraclavicular fossa). Finally, it should be mentioned that the five-year and 10-year survival rates in our cases of pharyngeal lymphoma in the local and regional stages were similar to those reported respectively for stage 1 and stage 2 cases of primary lymphosarcoma and reticulum cell sarcoma in the lymph nodes (Easson, 1966; Peters, 1963).

Whether prophylactic irradiation should include the axillae, mediastinum, or stomach is debatable. It could be argued that when this type of lymphoma has spread beyond the local or regional stage a vascular rather than a lymphatic progression occurs. In patients with diffuse disease the five-year survival is very low. For this reason we treat these patients at present with intensive combined chemotherapy for six months and then consolidate the treatment with cobalt irradiation to the head, neck, and abdominal region. Finally, chemotherapy followed by radiotherapy is also indicated whenever there is gastric involvement. Since the lymphomatous lesions of the stomach tend to bleed a surgical resection should be carried out if possible before further treatment.

The authors wish to acknowledge the cooperation of S. Ceccarini in the preparation of the figures.

Requests for reprints should be sent to Dr. G. Bonadonna, via Venezian 1, Milan 20133, Italy.

\section{References}

Al-Saleem, T., Harwick, R., Robbins, R., and Blady, J. V. (1970). Cancer (Philadelphia), 26, 1383 .

Banfi, A., Bonadonna, G., Carnevali, G., Oldini, C., and Salvini, E. (1968). European Fournal of Cancer, $4,319$.

Banfi, A., et al. (1970). Cancer (Philadelphia), 26, 341.

Carnevali, G., and Salvini, E. (1968). Tumori, 54, 135.

Catlin, D. (1966). Surgery, 60,1060.

Catlin, D. (1966). Surgery, 60, 1060. Medicine, 17, 179

Fuller, L. M. (1967). American Fournal of Roentgenology, 99, 340.

Fuller, L. M. (1967). American fournal

Luzzatti, G. (1960). Tumori, 46, 383.

McNelis, F. L., and Pai, V. T. (1969). Laryngoscope, 79, 1076. usshoff, K., Schmidt-Vollm
fournal of Cancer, 7, 451.

Peters, M. V. (1963). American fournal of Roentgenology, 90, 956.

Prosnitz, L. R., Hellman, S., Von Essen, C. F., and Kligerman, M. M. (1969). American fournal of Roentgenology, 105, 618.

Robinson, T., Fischer, J. J., and Vera, R. (1971). Radiology, 99, 669.

Rosenberg, S. A., Diamond, H. D., Jaslowitz, B., and Craver, L. F. (1961). Medicine, 40, 31

Terz, J. J., and Farr, H. W. (1969). Surgery, 65, 772.

Tikka, U., and Malmio, K. (1969). Acta Radiologica, 8, 459.

Wang, C. C. (1969). Radiology, 92, 1335. 